\title{
Field Experiment and Data Analysis of a Constant-Head Injection Test with Skin Effects in a Low-Transmissivity Aquifer
}

\author{
Chien-Chieh Chang ${ }^{1}$ and Chia-Shyun Chen ${ }^{1, *}$ \\ (Manuscript received 8 March 2001, in final form 20 January 2002)
}

\begin{abstract}
In a confined, silty sand aquifer of low transmissivity, constant-rate pumping can rapidly dewater the pumping well without creating measurable drawdown at nearby observation wells. To overcome this difficulty, a constant-head test is performed by overflowing the test well by water injection. The difference between the injection rate and the overflow rate directly gives the cumulative volume $V_{w}(t)$ entering the aquifer, which is characteristic of the aquifer hydrogeologic properties and can be used for parameter estimation. The field experiments include two constant-head injection tests, CHIT1 and CHIT2, performed at two different wells, respectively. Semilog plot of $t / \mathrm{V}_{\mathrm{w}}(\mathrm{t})$ of CHIT2 indicates little or no skin, and the two unknown parameters of the storage coefficient and transmissivity can be uniquely determined in a similar way by the well-known Jacob semilog method. Semilog plot of $t / \mathrm{V}_{w}(t)$ of CHIT1, however, shows the existence of well skin, and a curve matching method is developed for estimating the four pertinent parameters. Among them, the aquifer transmissivity can be uniquely determined while the skin transmissivity, the skin thickness, and the storage coefficient are obtained in appropriate ranges. To avoid non-unique estimates of aquifer parameters, therefore, the test well should be carefully constructed with complete and thorough well development to prevent skin region from happening. Due to the limitation of the site hydrogeology, only slug tests can be performed for the sake of validating transmissivity. The transmissivity values determined from the CHITs and from the slug tests are in good agreement, supporting the usefulness of the CHIT. The aquifer transmissivities estimated from CHIT1 and CHIT2 are within $14 \%$ difference, indicating that the aquifer is relatively homogeneous in the neighborhood of the two test wells.
\end{abstract}

(Key words: Constant-head test, Injection, Well skin, Parameter estimation)

\footnotetext{
${ }^{1}$ Institute of Applied Geology, National Central University, Chung-li, Taiwan, ROC

*Corresponding author address: Prof. Chia-Shyun Chen, Institute of Applied Geology, National Central University, Chung-Li, 32054 Taiwan, ROC; E-mail: chenchia@cc.ncu.edu.tw
} 


\section{INTRODUCTION}

There are two kinds of pumping tests, the constant-rate test (CRT) and the constant-head test (CHT), which can be used for aquifer parameter estimation. The CRT is a multiple-well test in which groundwater is withdrawn at a constant rate $\mathrm{Q}$ at the pumping well, and drawdown at observation wells is measured for parameter estimation. The CHT, however, is frequently performed in a single well, in which groundwater extraction is achieved by lowering a constant head $h_{w}$, and the transient flow rate $Q_{w}(t)$ is measured for parameter estimation (Kruseman and de Ridder 1990). In comparison to the CHT, the CRT has received much attention and many well hydraulics theories have been focused on it (Streltsova 1988; Kruseman and de Ridder 1990; Hantush 1964).

However, in low-transmissivity aquifers the CRT is not useful because it can easily result in "tight, deep cones of drawdown" (Freeze and Cherry 1979). Consequently, the CRT dewaters the pumping well within a short period of time without creating measurable drawdown at nearby observation wells for data analysis. For example, a CRT was performed at a 4-inch diameter well in the confined, silty sand aquifer at the Groundwater Research Well Field on campus. Before pumping, the water depth at the well was 23 meters, giving 180.6 liters of standing water in this well. The pumping rate used was as small as $22 \mathrm{~V} / \mathrm{min}$ and dried up the well in about 14.6 minutes with a total yield of 321.2 liters. As a result, the average groundwater flow rate entering the well was $9.63 \mathrm{l} / \mathrm{min}$. To keep the well flowing, $\mathrm{Q}$ must be less than 9 . $63 \mathrm{l} / \mathrm{min}$, which nevertheless produces little or no drawdown at a nearby observation well that is $5 \mathrm{~m}$ away. Therefore, the multiple well CRT is not suitable for this silty sand aquifer.

On the other hand, the CHT is particularly useful in aquifers of low transmissivity. This is because a fixed water level is maintained at the pumping well, so the well does not run dry. For example, geotechnical engineers employ the $\mathrm{CHT}$ to determine the hydraulic conductivity of clays (Wilkinson 1968; Tavenas et al. 1983, 1990; Novakowski 1993). Hydrogeologists also use it to estimate the aquifer transmissivity and the storage coefficient of weathered and unweathered glacial tills (Jones et al. 1992; Jones 1993). In petroleum engineering, however, the constant-head conditions are associated with oil production into a constant-pressure separator or pipeline, steam injection into a back pressured turbine, or flow to the atmosphere (EhligEconomides and Ramey 1981). In addition to these problems, many environmental incidents have created groundwater contamination in low-transmissivity aquifers in Taiwan. The investigation and remediation of these aquifers require knowledge of aquifer parameters, which can be appropriately estimated by the CHT. However, it is important to know that the CHT can also be used in aquifers of high transmissivity.

Well bore storage effect usually exists in a CRT. But, it does not occur in a CHT because the water depth at the test well is kept constant. Well bore storage adds one more unknown parameter to the data analysis. If the analysis does not properly handle well bore storage effect, it can easily account for the 1-2 orders of magnitude overestimation of specific storage (Mucha and Paulikova 1986; Narasimhan and Zhu 1993). Therefore, the CHT merits attention in practical application, especially when considering the estimation of the storage coefficient of the aquifer.

Only a few well hydraulics theories are available for the CHT. For confined conditions, 
Jacob and Lohman (1952) gave an analytical solution of $Q_{w}(t)$ in an infinite series, of which the large-time approximation is

$$
\frac{\mathrm{h}_{\mathrm{w}}}{\mathrm{Q}_{\mathrm{w}}(\mathrm{t})}=\frac{0.183}{\mathrm{~T}} \log \left(\frac{2.25 \mathrm{Tt}}{\mathrm{Sr}_{\mathrm{w}}^{2}}\right)
$$

The right-hand side of (1) is mathematically identical to the large time asymptotic solution of the well-known Theis solution for the CRT. By the semilog method given by Cooper and Jacob (1946), $T$ and $S$ can be determined with $h_{w} / Q_{w}(t)$. For the original infinite series solution, Murdoch and Franco (1994) gave an approximate solution that is easier to compute. For leaky aquifers, Hantush (1959) gave a solution for the CHT.

In practice, maintaining a constant water level at a well and measuring its flow rate may not be easy (e.g., see Tavenas et al. 1990; Jones et al. 1992). To deal with these difficulties, a constant-head injection test (CHIT) was developed in which the test well was injected and overflowed with surface water. This overflow at the top of the well ensures a constant head. The difference between the injection rate and the overflow rate gives the cumulative volume $V_{w}(t)$ that enters the aquifer. Since no groundwater is withdrawn, no surface treatment of contaminated groundwater is needed, which is an advantage for characterizing contaminated aquifers if injection of water is allowed.

The cumulative volume $V_{w}(t)$ is the integration of $Q_{w}(t)$ with respect to time,

$$
V_{w}(t)=\int_{0}^{t} Q_{w}(x) d x
$$

For a homogeneous condition, van Everdingen and Hurst (1949) gave an analytical solution of $V_{w}(t)$. They mentioned that $V_{w}(t)$ was useful in checking the material balance when analyzing the pressure behavior of a reservoir. Uraiet and Raghavan (1980) used $V_{w}(t)$ in determining the average reservoir pressure before the onset of possible boundary effects. Olarewaju and Lee(1989) noted that $V_{w}(t)$ could be useful for production forecast. So far, $V_{w}(t)$ has not been used to estimate the aquifer parameters. For the CHIT, therefore, it is needed to develop parameter estimation methods of using $\mathrm{V}_{w}(t)$.

Furthermore, drilling in Taiwan usually involves using drilling mud, especially when utilizing the cable-tool percussion method. The drilling mud can permeate the porous materials surrounding the borehole. When the aquifer has a low transmissivity, the processes of well development usually cannot completely remove the invading drilling mud. The porous media containing the residual drilling mud forms the so-called skin region. The thickness of the skin region can range from a few millimeters to several meters (Novakowski 1989). At observation wells, the influence of the skin region diminishes with the increasing pumping time (Novakowski 1989; Chu et al. 1980). At the pumping well, however, the skin effects never disappear (van Everdingen 1953; Streltsova 1988; Olarewaju and Lee 1989). Therefore, the single-well constant head test must take into account the skin effects, if the skin region exists.

If the transmissivity of the skin region is less than that of the native aquifer, the skin region is called a positive skin; in opposite cases, it is called a negative skin. In mathematical models, the infinitesimal skin approach and the finite skin approach are used to study the skin effects. The infinitesimal skin approach assumes that the skin region has an infinitesimal 
thickness, and the associated skin effects are lumped into a single parameter called the skin factor $S_{k}$ (e.g., van Everdingen 1953; Earlougher 1977; Streltsova 1988). Using this approach, Hurst et al. (1969) gave the Laplace-domain solution of the cumulative volume of a constanthead well,

$$
\mathrm{V}_{\mathrm{w}}(\mathrm{p})=\frac{\mathrm{K}_{1}(\sqrt{\mathrm{p}})}{\mathrm{p}^{3 / 2}\left[\mathrm{~K}_{0}(\sqrt{\mathrm{p}})+\mathrm{S}_{\mathrm{k}} \sqrt{\mathrm{p}} \mathrm{K}_{1}(\sqrt{\mathrm{p}})\right]}
$$

where $\mathrm{p}$ is the Laplace transform parameter of the dimensionless time $\tau$.

In (3), $S_{k}$ is positive for positive skin, and zero for no skin. However, (3) cannot be used to deal with negative skin by setting $S_{k}$ negative because $V_{w}(t)$ would be less than zero if $S_{k}$ were negative (Hurst et al. 1969). When working with negative skin, the finite skin approach is particularly useful. As shown in Fig. 1, the finite skin region extends from $r_{w}$ to $r_{s}$ with a transmissivity $\mathrm{T}_{\mathrm{s}}$, and the native aquifer exists beyond $\mathrm{r}_{\mathrm{s}}$ with a transmissivity $\mathrm{T}$. As far as the storage coefficients of the aquifer and of the skin region are concemed, no field evidence has ever indicated that they must be different. In fact, Olarewaju and Lee (1989), and Novakowski (1989) assumed them to be the same.

The finite skin approach is also applicable for positive skin. For the CRT (Hawkins 1956) and the CHT (Uraiet and Raghavan 1980), $S_{k}$ of the infinitesimal skin approach is related to pertinent parameters of the finite skin approach as

$$
S_{k}=\left(\frac{T}{T_{s}}-1\right) \ln \frac{r_{s}}{r_{w}}=(\alpha-1) \ln \rho_{s}
$$

The above relation is appropriate when groundwater flow in the skin region reaches the steady state.

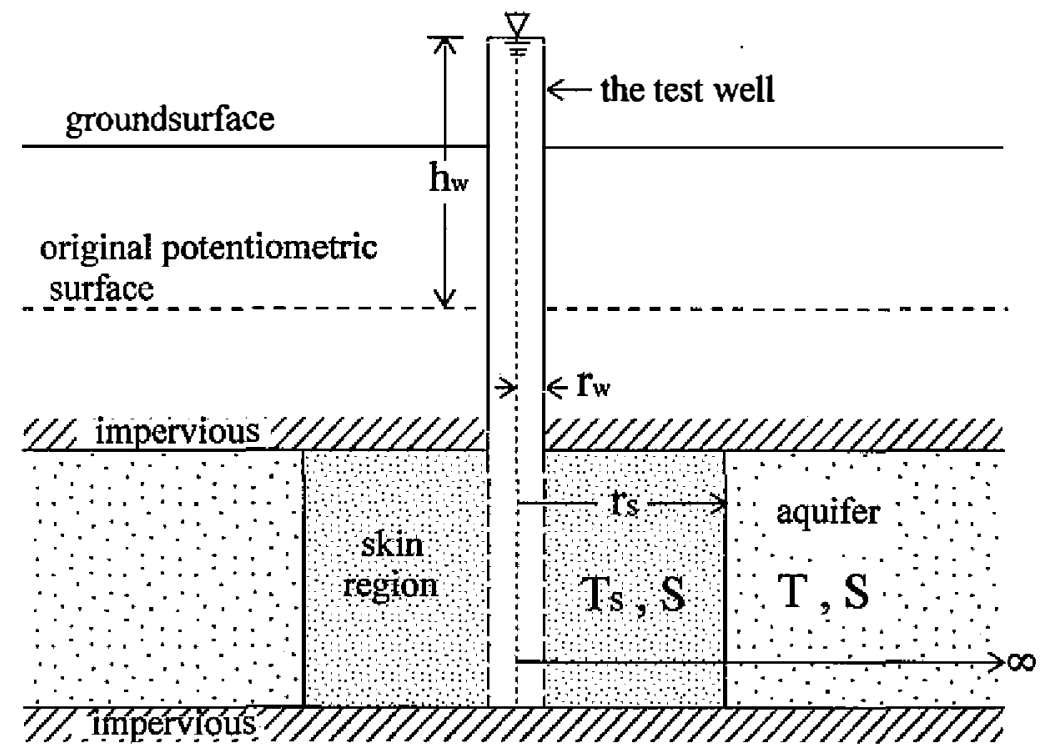

Fig. 1. Schematic illustration of the finite skin model. 
The CHIT needs to develop parameter estimation methods of using $\mathrm{V}_{\mathrm{w}}(\mathrm{t})$. The possible skin effects are taken into account by the finite skin approach, where the aquifer storage coefficient and the skin storage coefficient are assumed to be the same $\mathrm{S}$. Therefore, a total of four parameters, $T, T, S$, and $r_{s}$, are to be determined. The purposes of this paper are to develop parameter estimation methods of using $\mathrm{V}_{\mathrm{w}}(\mathrm{t})$, to discuss the field experiment of the CHIT, and to determine the pertinent parameters of the silty sand aquifer from the field data of cumulative volumes from two CHITs.

\section{THEORETICAL ANALYSIS}

\subsection{The Semi-Analytical Solution}

For the finite skin model shown in Fig. 1, Novakowski (1993) gives the Laplace domain solution of the dimensionless flow rate in the constant-head well as

$$
Q_{w}(p)=\frac{1}{\sqrt{p \alpha}} \frac{\varphi_{2} K_{1}(\sqrt{p \alpha})+\varphi_{1} I_{1}(\sqrt{p \alpha})}{\varphi_{2} K_{0}(\sqrt{p \alpha})+\varphi_{1} I_{0}(\sqrt{p \alpha})}
$$

The cumulative volume in the Laplace domain can be easily determined from $Q_{w}(p)$ by the following relation (Wylie and Barrett 1982; p.411),

$$
\mathrm{V}_{\mathrm{w}}(\mathrm{p})=\mathrm{L}\left\{\int_{0}^{\tau} \mathrm{Q}_{\mathrm{w}}(\mathrm{x}) \mathrm{dx}\right\}=\frac{\mathrm{Q}_{\mathrm{w}}(\mathrm{p})}{\mathrm{p}} .
$$

Therefore, dimensionless $V_{w}(p)$ with the presence of finite skin is obtained by dividing $Q_{w}(p)$ of (5) by $p$,

$$
\mathrm{V}_{\mathrm{w}}(\mathrm{p})=\frac{1}{\mathrm{p}^{3 / 2} \sqrt{\alpha}} \frac{\varphi_{2} \mathrm{~K}_{1}(\sqrt{\mathrm{p} \alpha})+\varphi_{1} \mathrm{I}_{1}(\sqrt{\mathrm{p} \alpha})}{\varphi_{2} \mathrm{~K}_{0}(\sqrt{\mathrm{p} \alpha})+\varphi_{1} \mathrm{I}_{0}(\sqrt{\mathrm{p} \alpha})}
$$

In the following discussion, Laplace inversion of $\mathrm{V}_{w}(p)$ or other Laplace-domain solutions are numerically carried out by the Stehfest(1970) method.

\subsection{Characteristics of $\tau / N_{w}(\tau)$}

Once the constant-head injection starts, the head of groundwater begins to build up in the vicinity of the test well, then the cone of head buildup expands outward. During an early time period, the cone of head buildup stays within the skin region. During an intermediate time span, the cone of head buildup moves across the boundary between the skin region and the aquifer. At later times, the cone of head buildup moves into the aquifer. The temporal variation of $\mathrm{V}_{\mathrm{w}}$, in terms of $\tau / \mathrm{N}_{\mathrm{w}}(\tau)$, can reflect the hydrogeological properties of the medium through which the cone of head buildup passes.

Figure 2 illustrates the characteristics of logarithmic $\tau / \mathrm{V}_{\mathrm{w}}(\tau)$ useful for the determination of parameters. When there is no skin, the aquifer becomes homogeneous and $\alpha=\rho_{s}=1$. For this homogeneous case, the logarithmic $\tau / V_{w}(\tau)$ presents a smooth curve with a straight- 


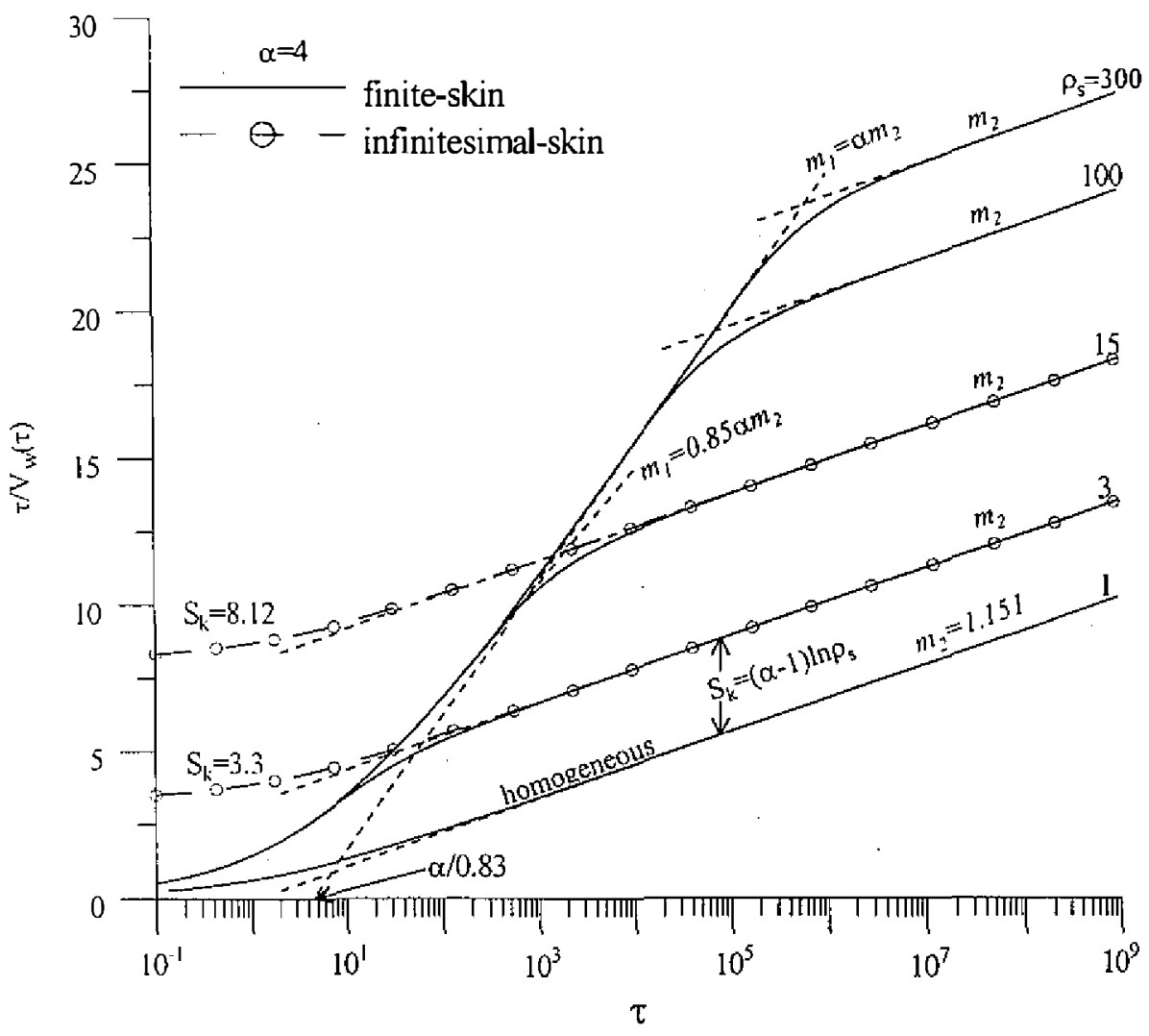

Fig. 2. Semilog plot of $\tau / \mathrm{N}_{\mathrm{w}}(\tau)$ showing the influence of skin region and the linear characteristics. Also, comparison of infinitesimal skin approach to the finite skin approach was made for $\rho_{\mathrm{s}}=3$ and 15 .

line tail for $\tau$ greater than $10^{3}$. The slope of this tail is 1.151 as measured in Fig. 2. By regression analysis, this tail can be expressed by

$$
\frac{\tau}{\mathrm{V}_{\mathrm{w}}(\tau)}=1.151 \log (0.83 \tau)
$$

of which the dimensional form is

$$
\frac{\mathrm{t}}{\mathrm{V}_{\mathrm{w}}(\mathrm{t})}=\frac{0.183}{\mathrm{Th}_{\mathrm{w}}}\left[\log \left(\frac{0.83 \mathrm{Tt}}{\mathrm{Sr}_{\mathrm{w}}^{2}}\right)\right]
$$

According to (2), differentiation of $V_{w}(t)$ with respect to time gives $Q_{w}(t)$. Differentiating $V_{w}$ ( $t$ ) of $(8 \mathrm{~b})$ and rearranging terms afterwards results in (1), validating the regression relations of (8).

If well skin exists, $\tau / V_{w}(\tau)$ becomes dependent on $\rho_{s}$. When $\rho_{s}$ is small (e.g., $\rho_{s}=3$ ), the curve is similar to that of the homogeneous case. However, when $\rho_{\mathrm{s}}$ increases (e.g., $\rho_{\mathrm{s}}=$ 15,100 , or 300 ), the associated curves exhibit a pattern in which an early-time and a late-time 
straight lines are joined by a smooth transitional curve. All the late-time straight lines are parallel to a constant slope of 1.151. Moreover, the vertical distance between the late-time straight line of $\rho_{s}=1$ and any late-time straight line of $\rho_{s}>1$ is equal to $S_{k}$ as defined in (4). Hence, the late-time straight line for $\rho_{s}>1$ can be expressed by adding (4) to (8), or

$$
\frac{\tau}{\mathrm{V}_{\mathrm{w}}(\tau)}=1.151 \log (0.83 \tau)+\mathrm{S}_{\mathrm{k}}=0.5 \ln (0.83 \tau)+\mathrm{S}_{\mathrm{k}}
$$

Figure 2 shows that each early-time straight line has a specific slope of $m_{1}$, which is proportional to the slope of the late-time straight line, $m_{2}$. It should be emphasized that $m_{2}$ is always 1.151 on semilog plot of $\tau / \mathrm{V}_{\mathrm{w}}(\tau)$. However, if $\rho_{\mathrm{s}}$ is large (e.g., $\rho_{\mathrm{s}}=100$ and 300 ), $\mathrm{m}_{1} / \mathrm{m}_{2}$ is exactly equal to $\alpha$, and thus $\mathrm{m}_{1}$ is $1.151 \alpha$. The early-time straight line of a large $\rho_{\mathrm{s}}$ intercepts the logarithmic axis at $\tau=\alpha / 0.83$, as shown in Fig. 2. As a result, the early-time straight lines for a large $\rho_{s}$ can be expressed by

$$
\frac{\tau}{\mathrm{V}_{\mathrm{w}}(\tau)}=1.15 \log \log (0.83 \tau / \alpha)
$$

The dimensional form of (10) is independent of the aquifer properties because the constant-head injection's influence stays within the skin region at early times. For $15<\rho_{\mathrm{s}}<100$, $\mathrm{m}_{1} / \mathrm{m}_{2}$ is no longer equal to $\alpha$, but increases from 0.85 to $1.0 \alpha$. Thus, the corresponding values for $\mathrm{T} / \mathrm{T}_{s}$ range from $1.0 \mathrm{~m}_{1} / \mathrm{m}_{2}$ to $1.18 \mathrm{~m}_{1} / \mathrm{m}_{2}$. Due to the changing $\mathrm{m}_{1}$, the regression relations for the early-time straight lines cannot be easily identified. If $\rho_{\mathrm{s}}$ is small, however, the early-time straight line does not exist.

The difference between the infinitesimal skin approach and the finite skin approach can be understood by comparing $\tau / \mathrm{V}_{\mathrm{w}}(\tau)$ determined with (3) and (7). Setting $\rho_{\mathrm{s}}$ to 3 , these two approaches yield congruent results, except when $\tau$ is less than $10^{3}$. This early-time deviation results from the infinitesimal skin approach assuming a steady-state groundwater flow in the skin region, while the finite skin approach does not (Uraiet and Raghavan 1980). When $\rho_{\mathrm{s}}$ is increased to $15,(3)$ is only valid for the late-time straight line as $\tau$ is greater than $5 \times 10^{4}$. For $\tau$ less than $5 \times 10^{4}$, the infinitesimal skin approach yields a smooth curve, while the finite skin approach gives a straight line approximation. Therefore, if the field data of semilog $t / V_{w}(t)$ does not show a straight line at early time, the skin thickness is relatively small and can be ignored, or the infinitesimal skin approach should be used in such instances. But, when both the early-time and late-time straight lines appear, the skin thickness cannot be neglected and the finite skin approach should be used.

The so-called pressure derivative data $\mathrm{dP} / \mathrm{d}(\mathrm{logt})$ are frequently used in petroleum engineering to investigate the oil pressure variation (e.g., Bourdet et al.1989; Tiab and Kumar1980). Here, the derivative data of $\tau / \mathrm{V}_{\mathrm{w}}(\tau)$ are defined as $\mathrm{d}\left[\tau / \mathrm{V}_{\mathrm{w}}(\tau)\right] / \mathrm{d}(\log \tau)$, which explicitly expresses how $\tau / \mathrm{V}_{\mathrm{w}}(\tau)$ varies with logarithmic $\tau$ on semilog paper. For example, when the derivative data $\mathrm{d}\left[\tau / \mathrm{V}_{\mathrm{w}}(\tau)\right] / \mathrm{d}(\log \tau)$ become constant, $\tau / \mathrm{V}_{\mathrm{w}}(\tau)$ on semilog paper is a straight line with a slope equal to the constant value of $\mathrm{d}\left[\tau / \mathrm{V}_{\mathrm{w}}(\tau)\right] / \mathrm{d}(\log \tau)$. When $\mathrm{d}\left[\tau / \mathrm{V}_{\mathrm{w}}(\tau)\right] / \mathrm{d}(\log$ $(\tau)$ changes slowly, $\tau / \mathrm{V}_{\mathrm{w}}(\tau)$ can be approximated by a staight line on semilog paper. When $\mathrm{d}\left[\tau / \mathrm{V}_{\mathrm{w}}(\tau)\right] / \mathrm{d}(\log \tau)$ changes rapidly, $\tau / \mathrm{V}_{\mathrm{w}}(\tau)$ cannot be a straight line on semilog paper.

As shown in Fig. 3, when $\rho_{s}$ is 300 , the derivative data curve reaches a limiting value of 


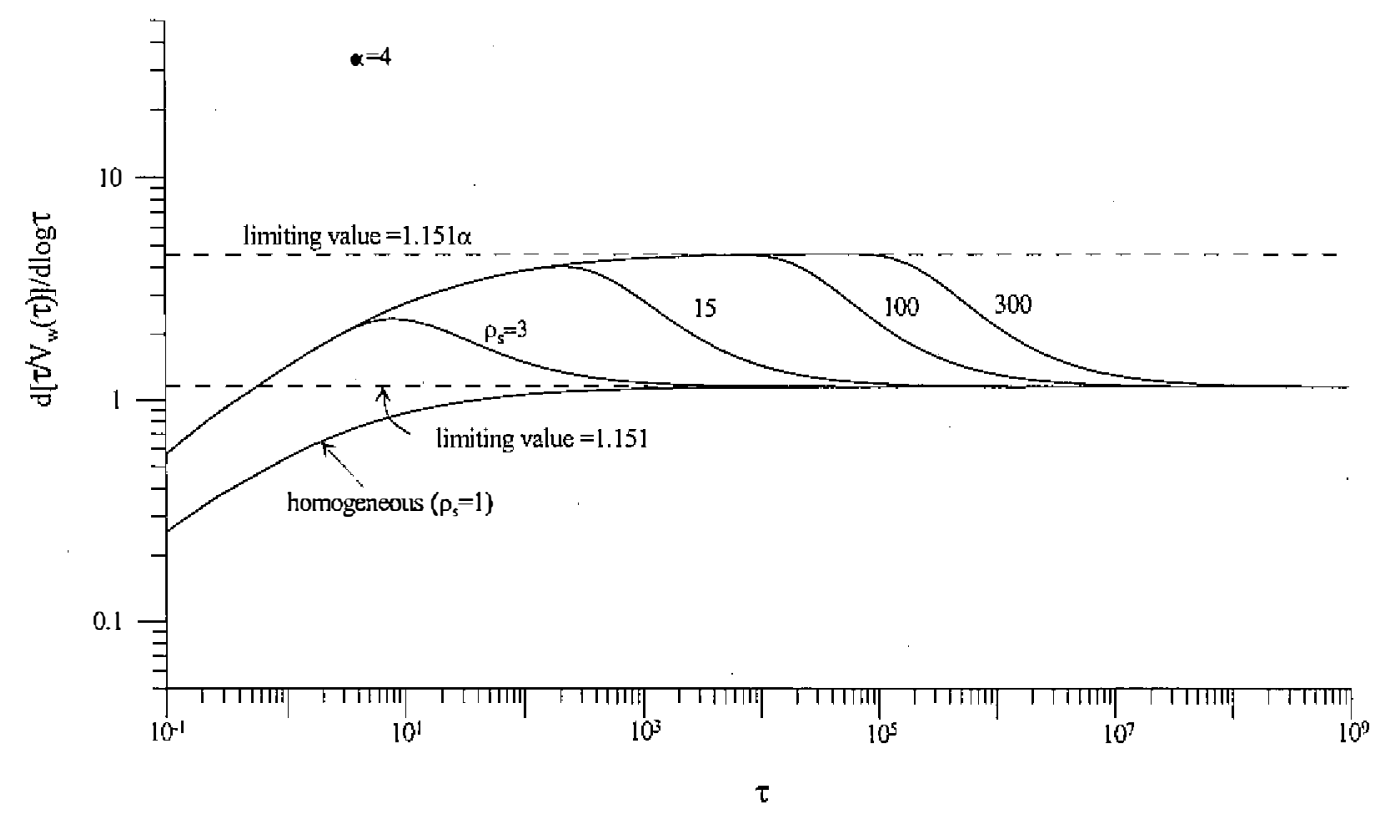

Fig. 3. Derivative data of $\tau / \mathrm{V}_{\mathrm{w}}(\tau)$ for a fixed $\alpha$ and different $\rho_{\mathrm{s}}$.

$1.151 \alpha$ for $10^{4}<\tau<10^{5}$. This verifies that the early-time straight line has a slope $1.151 \alpha$ as indicated in Fig. 2. For $\tau$ greater than approximately $10^{8}$, the derivative data curve reaches another limiting value of 1.151 , comfirming that the late-time straight line on semilog paper has a constant slope 1.151. For $10^{5}<\tau<10^{8}$, the derivative data curve continues to change, representative of a transitional curve joining the early-time and the late-time straight lines on semilog plot of $\tau / \mathrm{V}_{\mathrm{w}}(\tau)$.

As $\rho_{\text {s }}$ is 15 , the derivative data curve varies slowly for $40<\tau<200$, during which $d$ $\left[\tau / \mathrm{V}_{\mathrm{w}}(\tau)\right] / \mathrm{d}(\log \tau)$ is approximately $85 \%$ of the limiting value $1.151 \alpha$. As $\rho_{\mathrm{s}}$ is 100 , the derivative data curve for $10^{3}<\tau<10^{4}$ is nearly $1.151 \alpha$. Therefore, as $\rho_{\mathrm{s}}$ varies from 15 to 100 , semilog $\tau / \mathrm{V}_{\mathrm{w}}(\tau)$ for small $\tau$ can be approximated by a straight line, of which the slope changes from 0.98 to $1.151 \alpha$. However, the derivative data curves for $\tau$ greater than $10^{5}$ reach a constant 1.151. This confirms that the late-time straight lines of semilog $\tau / \mathrm{V}_{\mathrm{w}}(\tau)$ have a constant slope 1.151. As $\rho_{s}$ is 3 and 1 , the derivative data curves vary relatively rapidly before reaching the limiting value 1.151 for $\tau$ greater than $10^{3}$. This indicates that semilog $\tau / \mathrm{V}_{\mathrm{w}}(\tau)$ is a smooth curve with a straight line tail at large $\tau$, for $\rho_{\mathrm{s}}$ being small.

In summary, if semilog plot of field data $t / V_{w}(t)$ demonstrates early-time and late-time straight lines joined by a transitional curve, the skin thickness is relatively large (i.e., $\rho_{s}>15$ or $r_{s}>15 r_{w}$ ), and the finite skin approach should be used for data analysis. The ratio of the slope of the early-time straight line, $m_{1}$, to the slope of the late-time straight line, $m_{2}$, is related to the wansmissivity ratio $\alpha\left(\alpha=\mathrm{T} / \mathrm{T}\right.$ ) . If $\rho_{\mathrm{s}}$ is greater than 100 (i.e., $\left.\mathrm{r}_{\mathrm{s}}>100 \mathrm{r}_{\mathrm{w}}\right), \mathrm{m}_{1} / \mathrm{m}_{2}$ is equal to $\alpha$. Under most field conditions, however, the skin thickness $r_{s}$ is not likely to be greater than $100 r_{w}$, and $m_{1} / m_{2}$ can be generally assumed to vary from 0.85 to $1.0 \alpha$. The possible range of $\mathrm{T} / \mathrm{T}_{\mathrm{s}}$ can thus be assumed to change from $1.0 \mathrm{~m}_{1} / \mathrm{m}_{2}$ to $1.18 \mathrm{~m}_{1} / \mathrm{m}_{2}$. When semilog plot of field 
data $t / \mathrm{V}_{w}(t)$ shows a smooth curve with a straight line tail at large times, the skin region is relatively thin that it can be either ignored or studied using the infinitesimal-skin approach.

\subsection{Development of Parameter Estimation Method}

The cumulative volumes are measured in real time, and the above dimensionless analysis must be converted into the dimensional analysis for parameter estimation. Writing (9) in the dimensional form gives $\mathrm{t} / \mathrm{V}_{\mathrm{w}}(\mathrm{t})$ of large times,

$$
\frac{\mathrm{t}}{\mathrm{V}_{\mathrm{w}}(\mathrm{t})}=\frac{0.183}{\mathrm{Th}_{\mathrm{w}}}\left[\log \left(\frac{0.83 \mathrm{Tt}}{\mathrm{Sr}_{\mathrm{w}}^{2}}\right)+2\left(\frac{\mathrm{T}}{\mathrm{T}_{\mathrm{s}}}-1\right) \log \frac{\mathrm{r}_{\mathrm{s}}}{\mathrm{r}_{\mathrm{w}}}\right]
$$

The straight line expressed by (11) intercepts the abscissa of logarithmic time at

$$
\mathrm{t}_{2}=1.205 \frac{\mathrm{Sr}_{\mathrm{w}}^{2}}{\mathrm{~T}}\left(\frac{\mathrm{r}_{\mathrm{w}}}{\mathrm{r}_{\mathrm{s}}}\right)^{2\left(\mathrm{~T} / \mathrm{T}_{\mathrm{s}}-1\right)},
$$

and the slope of $(11)$ is

$$
\mathrm{m}_{2}=\frac{0.183}{\mathrm{Th}_{\mathrm{w}}} .
$$

The procedures of the curve matching method are given below.

1. Prepare the field data curve by plotting $2 \pi T h_{w}\left[t / V_{w}(t)\right]$ against logarithmic time on semilog paper. Determine the slope $m_{1}$ of the early-time straight line, and the slope $m_{2}$ of the latetime straight line. By (13), $\mathrm{T}$ can be uniquely determined with $\mathrm{m}_{2}$. It should be noted that field data curves prepared in terms of $2 \pi \mathrm{Th}_{w}\left[t / \mathrm{V}_{w}(t)\right]$ are of the same magnitude as the curves of semilog $\tau / \mathrm{V}_{\mathrm{w}}(\tau)$; this is conducive to curve matching.

2. Estimate the possible range of $\rho_{s}$ by rewriting (12) as

$$
\rho_{\mathrm{s}}=\left[1.205 \frac{\mathrm{Sr}_{\mathrm{w}}^{2}}{\mathrm{Tt}_{2}}\right]^{\frac{1}{2(\alpha-1)}} \text {. }
$$

The typical values for S range from $10^{-3}$ to $10^{-5}$ (Bear 1972; Freeze and Cherry 1979). The possible range for $\alpha$ lies between $\mathrm{m}_{1} / \mathrm{m}_{2}$ and $1.18 \mathrm{~m}_{1} / \mathrm{m}_{2}$, as discussed above. The unique value of T is known from Step 1. Consequently, the appropriate range of $\rho_{\mathrm{s}}$ can be determined using (14).

3. Prepare type curves by plotting $\tau / \mathrm{V}_{\mathrm{w}}(\tau)$ against logarithmic $\tau$ on semilog paper. This is the same scale used for the field data curve. On each type curve paper, an $\alpha$ value between $m_{\mathrm{j}} l$ $\mathrm{m}_{2}$ and $1.18 \mathrm{~m}_{1} / \mathrm{m}_{2}$ is selected. Associated with this $\alpha$ are type curves of $\rho_{\mathrm{s}}$ that fall in the range determined by (14) in Step 2.

4. Overlay the field data curve paper onto one type curve paper by keeping the abscissa of logarithmic $t$ coincident with the abscissa of logarithmic $\tau$. Shift the field data curve paper horizontally until the field data are matched by one of the type curves of a specific $\rho_{s}$. At this matched position, read an arbitrary pair of $t_{m}$ and $\tau_{m}$ from the abscissa of logarithmic $t$ and logarithmic $\tau$, respectively. If a matched position cannot be found, the type curve paper 
in use should be disregarded. New type curve paper of a different $\alpha$ is then used until a matched position is found.

5. Determine $S$ by the pair of $\tau_{\mathrm{m}}$ and $\mathrm{t}_{\mathrm{m}}$ in the following way:

$$
\mathrm{S}=\frac{\mathrm{Tt}_{\mathrm{m}}}{\mathrm{r}_{\mathrm{w}}^{2} \tau_{\mathrm{m}}}
$$

6. Determine $T_{s}$ using the definition of $\alpha$ as

$$
\mathrm{T}_{\mathrm{s}}=\mathrm{T} / \alpha
$$

7. Determine $r_{s}$ using the definition of $\rho_{s}$ as

$$
r_{s}=p_{s} r_{w}
$$

Curve matching is then repeated to find a new set of $r_{s}, T_{s}$, and $S$. Although time consuming, this curve matching method yields appropriate ranges for $S, T_{s}$ and $r_{s}$ relatively easily. If the semilog plot of $t / V_{w}(t)$ shows no early-time straight line but only a late-time straight line, the skin effects can be ignored, and only $\mathrm{T}$ and $\mathrm{S}$ are to be determined. By ( $8 \mathrm{~b}), \mathrm{T}$ is determined from the slope of the late-time straight line, $\mathrm{m}_{2}$, using (13). And, $S$ is determined form the intercept, $t_{2}$, using (12) but let $r_{s}$ equal $r_{w}$ and $T_{s}$ equal $T$.

\section{FIELD EXPERIMENTS}

\subsection{Site Hydrogeology}

As shown in Fig. 4, there are six multilevel well nests in the Groundwater Research Well Field on campus. The campus is on the Tao Yuan Tableland, a thick sequence of Pleistocene Table 1 and Gravels representative of rapid accumulations of erosion materials that have been (i.e., alluvial deposits) washed down from hilly regions (Juan 1954). These deposits consist of an upper sequence of a red-brown lateritic soil underlain by rounded boulder sized sandstone casts in an uncemented mixture of sand, silt and clay; there is also a lower sequence of interbedded, well consolidated sand, silt, and clay.

Each multilevel well nest is a 30-cm diameter borehole hosting three stainless steel 4-inch wells at different depths. In each nest, the first well has a wired screen of $8 \mathrm{~m}$ in the upper sand and gravel layer, the second a wired screen of $4 \mathrm{~m}$ in the upper silty sand layer, and the third a wired screen of $10 \mathrm{~m}$ across the lower silty sand layer. To avoid cross flow, bentonite was used to isolate the three wells in a nest. The six boreholes were drilled using the cable tool percussion method with drilling mud. The groundwater levels inside the first and the second wells were about 8 meters below the ground surface, indicating that the upper sand and gravel layer and the upper silty sand layer are hydraulically connected. The groundwater levels at all the third wells were about 10 meters below ground surface. Thus, the lower silty sand aquifer is under a confined condition independent of the above units by the upper clay layer. There were two CHITs performed at the third well of nest 2 (test well 1) and at the third well of nest 5 (test well 2). The lower silty sand aquifer is the target aquifer under examination, and it has an aquifer thickness $b$ of $10 \mathrm{~m}$. 
(a)

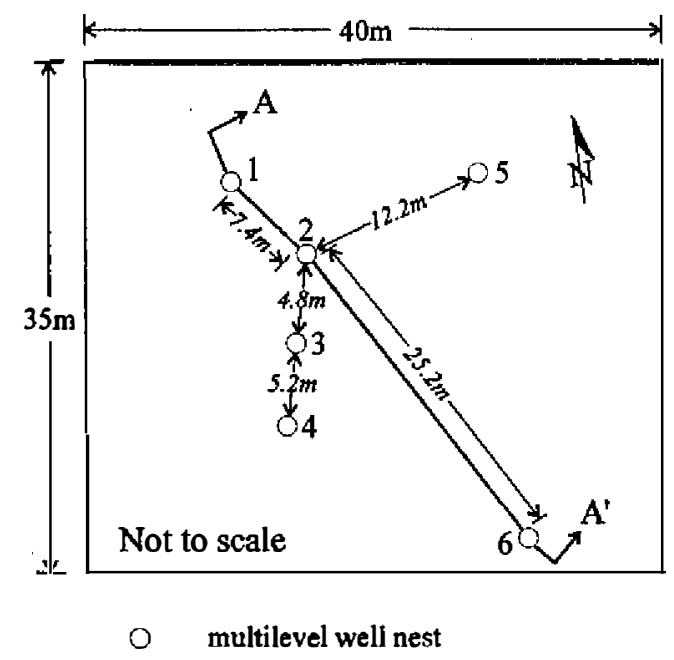

(b)

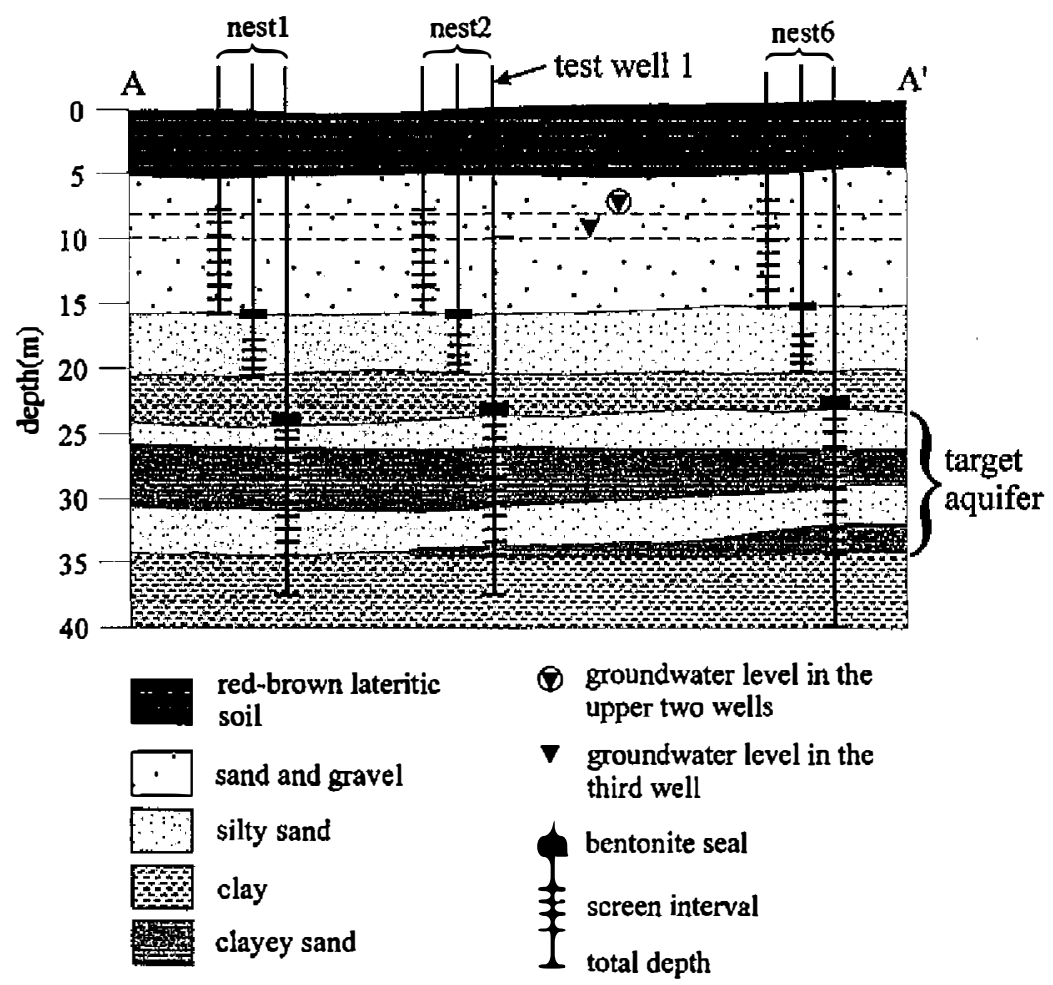

Fig. 4. Well locations and hydrogeological conditions of the Groundwater Research Well Field. (a) configuration of the multilevel well nests. (b) stratigraphy of cross section $\mathrm{AA}^{\prime}$. 
Table 1. Summary of the results of $T, T_{s}, r_{s}, S$ and $S_{k}$, and the matched information for four groups of curve matching.

\begin{tabular}{|c|c|c|c|c|c|c|c|}
\hline \multicolumn{4}{|c|}{ matched information } & \multicolumn{4}{|c|}{ results obtained } \\
\hline$\alpha$ & $\rho_{s}$ & $\begin{array}{c}\mathrm{t}_{\mathrm{m}} \\
(\mathrm{min})\end{array}$ & $\begin{array}{r}\tau_{n} \\
\times 10^{2}\end{array}$ & $\begin{array}{c}\mathrm{T}_{\mathrm{s}}=\frac{\mathrm{T}}{\alpha} \\
\times 10^{-4}\left(\mathrm{~m}^{2} / \mathrm{min}\right)\end{array}$ & $\begin{array}{c}r_{s}=\rho_{s} r_{w} \\
(m)\end{array}$ & $\begin{aligned} S= & \frac{T t_{m}}{r_{w}{ }^{2} \tau_{m}} \\
& \times 10^{-3}\end{aligned}$ & $S_{k}=(\alpha-1) \ln \rho_{s}$ \\
\hline 6.6 & 33 & 1 & 5.2 & 2.55 & 1.65 & 1.30 & 19.58 \\
\hline 7.0 & 27 & 1 & 4.0 & 2.40 & 1.35 & 1.68 & 19.76 \\
\hline 7.4 & 22 & 3 & 10.0 & 2.27 & 1.10 & 2.00 & 19.78 \\
\hline 7.9 & 18 & 3 & 8.0 & 2.13 & 0.90 & 2.52 & 19.94 \\
\hline \multicolumn{4}{|c|}{ average value } & 2.34 & 1.25 & 1.88 & 19.77 \\
\hline \multicolumn{8}{|c|}{$\mathrm{T}=1.68 \times 10^{-3} \mathrm{~m}^{2} / \mathrm{min}, \mathrm{r}_{\mathrm{w}}=0.05 \mathrm{~m}$} \\
\hline
\end{tabular}

\subsection{Experiment Facilities and Experiment}

As shown in Fig. 5, the CHIT system consists of three major parts: a water supply unit with a water storage tank and a discharge tank, a water weight measurement tank connected to an electronic balance and a personal computer, and an overflow control unit adjustable in length to give different constant heads for the test well. Prior to the CHIT, the water weight measurement tank was filled with water in a known weight, $\mathrm{W}_{\mathrm{o}}$. A fixed length of the overflow control unit was threaded onto the test well to ensure a constant buildup under the overflow condition.

During the CHIT, the water weight measurement tank feeds the test well through the overflow control unit at an inflow rate of $\mathrm{Q}_{j}(\mathrm{t})$. Under the given head, a portion of the injection water enters the silty sand aquifer at a flow rate of $Q_{w}(t)$, and the remainder returns to the water weight measurement tank at an overflow rate of $Q_{0}(t)$. The difference between $Q_{i}(t)$ and $Q_{0}(t)$ results in $Q_{w}(t)$. While $Q_{w}(t)$ decreases with time, $Q_{0}(t)$ increases with time as $Q_{i}(t)$ remains constant in a CHIT.

If water initially stored in the water weight measurement tank is sufficient to sustain the injection, replenishment of this tank is unnecessary. Otherwise, however, surface water is delivered to the water storage tank and then pumped to the discharge tank, maintaining a constant head of $\mathrm{H}_{\mathrm{T}}$. There are six discharge valves of different diameters at the bottom of the discharge tank. Their discharge rates against $\mathrm{H}_{\mathrm{T}}$ were pre-determined in the laboratory. With the six available discharge rates, a proper, known flow rate, $Q_{s}$, can be adjusted to replenish the water weight measurement tank without overfilling. 


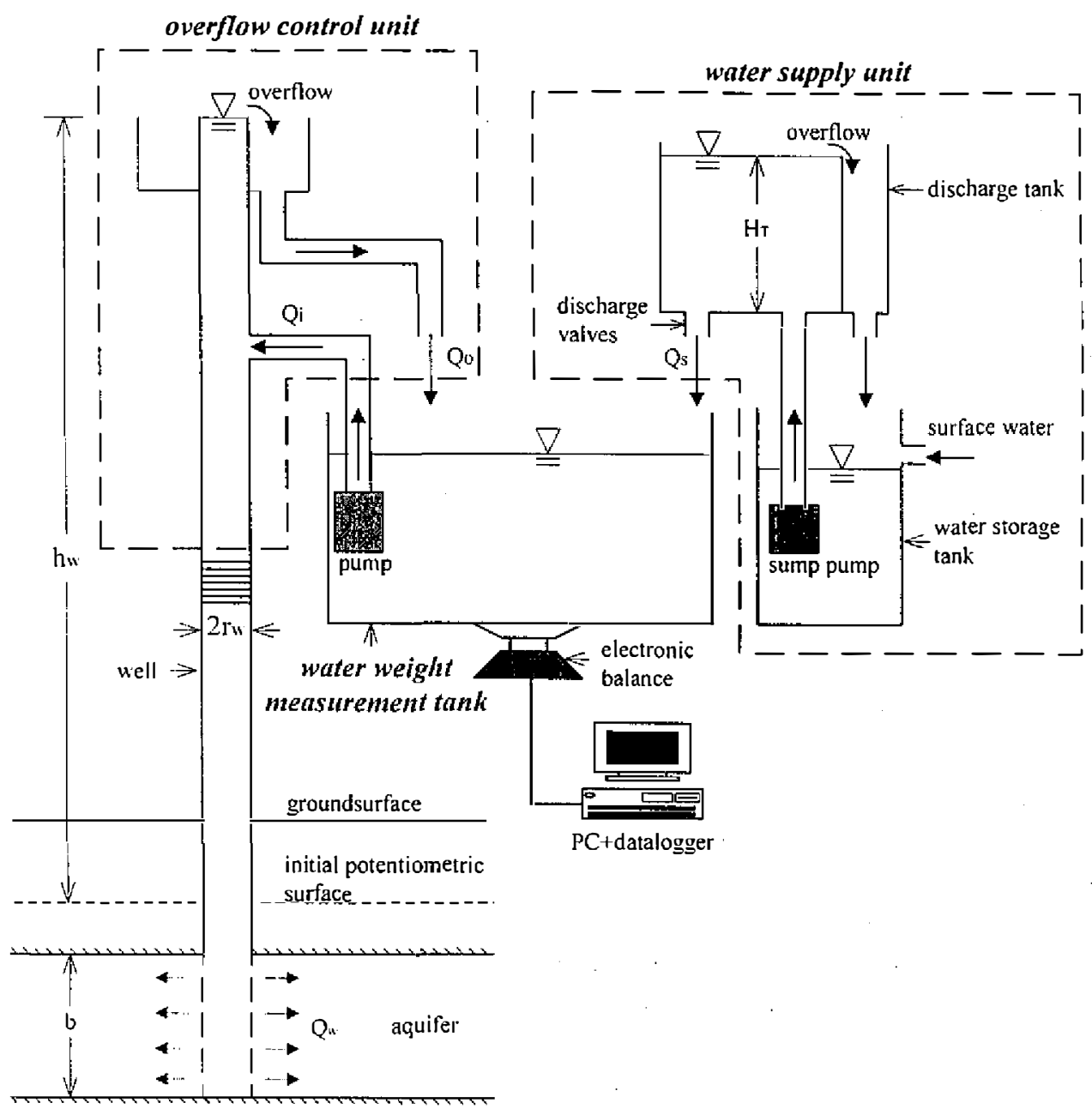

Fig. 5. Schematic illustration of the CHIT system.

Since $Q_{j}(t)$ and $Q_{o}(t)$ are unknown a priori, $Q_{w}(t)$ is determined by the water weight change inside the water weight measurement tank. If this tank is considered a control volume in which water compressibility is negligible under the atmospheric pressure, the mass balance principle gives

$$
\frac{d w(t)}{d t}=\gamma_{w}\left[Q_{s}+Q_{o}(t)-Q_{i}(t)\right]=\gamma_{w}\left[Q_{s}-Q_{w}(t)\right]
$$

or

$$
\mathrm{Q}_{\mathrm{w}}(\mathrm{t})=\mathrm{Q}_{\mathrm{s}}-\frac{1}{\gamma_{\mathrm{w}}} \frac{\mathrm{dw}(\mathrm{t})}{\mathrm{dt}},
$$

in which $w(t)$ is the water weight of the water weight measurement tank at any specific mea- 
suring time, and $\gamma_{w}$ is the specific weight of water. Differentiation of the measured $w(t)$ with respect to time amplifies the imbedded data noise, causing the data points of $Q_{w}(t)$ to scatter, thus rendering them unsuitable for data analysis. Integration of (18) with respect to time overcomes this problem and results in $\mathrm{V}_{w}(\mathrm{t})$,

$$
\mathrm{V}_{\mathrm{w}}(\mathrm{t})=\mathrm{Q}_{\mathrm{s}} \mathrm{t}-\frac{\mathrm{w}(\mathrm{t})-\mathrm{W}_{\mathrm{o}}}{\gamma_{\mathrm{w}}}
$$

Thus, the transient cumulative volume is used for parameter estimation. If the amount of water associated with $\mathrm{W}_{0}$ is sufficient for the experiment, $\mathrm{Q}_{\mathrm{s}}$ is set to zero during the test as well as in (19).

There were two CHITs, CHIT1 and CHIT2, performed in the lower silty sand aquifer with the CHIT system. With a constant head of $10.1 \mathrm{~m}$, CHIT1 ran for a total of 58 hours at test well 1 in April of 1998. In CHIT1, a total of $14.07 \mathrm{~m}^{3}$ surface water was injected into the aquifer, and $\mathrm{W}_{\mathrm{o}}$ was $307.1 \mathrm{kgw}$. Using $\mathrm{h}_{\mathrm{w}}=13.48 \mathrm{~m}, \mathrm{CHIT} 2$ ran for 67 hours at test well 2 in February of 1999 . A total of $71.05 \mathrm{~m}^{3}$ surface water was injected into the aquifer, and $\mathrm{W}_{\mathrm{o}}$ was $324.5 \mathrm{kgw}$ in CHIT2. These two tests had no bearing upon each other.

\subsection{Field Data Analysis}

Field data from the two CHITs are presented in Fig. 6. Because $h_{w}$ used in these two tests were different, the field data are presented in terms of $h_{w} t / V_{w}(t)$ instead of $t / V_{w}(t)$ for the sake of consistency. The field data of CHIT1 show an early-time straight line and a late-time straight line, indicating that a skin region exists around test well 1 with a possible thickness greater than $15 r_{w}$. Although the skin region exists, it is nonetheless useful to show errors in parameter estimation caused by ignoring the skin region. When doing so, only $\mathrm{T}$ and $\mathrm{S}$ are determined using the information from the late-time straight line. By the least square method, the slope $\mathrm{m}^{2}$ of the late-time straight line is $109 \mathrm{~min} / \mathrm{m}^{2}$. Thus, $\mathrm{T}$ is $1.68 \times 10^{-3} \mathrm{~m}^{2} / \mathrm{min}$ as determined by (13). The associated hydraulic conductivity is $2.8 \times 10^{-6} \mathrm{~m} / \mathrm{sec}$, which is appropriate for the silty sand aquifer (e.g., see Freeze and Cherry 1979). The intercept $t_{2}$ is $3.34 \times 10^{-20} \mathrm{~min}$. By setting $r_{s}$ equal to $r_{w}$ and $T_{s}$ to $T$ in (12), $S$ is determined to be $1.86 \times 10^{-20}$, an unreasonably small value. Therefore, if the skin region is neglected, $\mathrm{T}$ can be determined from the slope of the late-time straight line, but $S$ will be incorrectly estimated by the intercept of this line.

When well skin is taken into account, T remains unchanged as $1.68 \times 10^{-3} \mathrm{~m}^{2} / \mathrm{min}$. However, the possible range of $\alpha$ needs to be evaluated using the slopes of the early time and the latetime straight lines of the field data. Since the slope $m_{1}$ of the early-time straight line is determined by the least square method to be $717 \mathrm{~min} / \mathrm{m}^{3}$, the minimum possible $\alpha$ is $\mathrm{m}^{1} / \mathrm{m}^{2}$ or 6.6 , and the maximum possible $\alpha$ is $1.18 \mathrm{~m}_{1} / \mathrm{m}_{2}$ or 7.9 . By assuming $10^{-5}<\mathrm{S}<10^{-3}$ and $6.6<\alpha<7.9$, $\rho_{\mathrm{s}}$ is evaluated using (14) to be in the range of 15 to 33 .

After the appropriate ranges for $\alpha$ and $\rho_{\mathrm{s}}$ are determined, the type curves can be prepared. Although there are multiple combinations of $\alpha$ and $\rho_{s}$, usually a few groups of different $\alpha$ and $\rho_{\mathrm{s}}$ are sufficient. A total of four groups of type curves are used here. Each group has a specific $\alpha$; namely, $\alpha=6.6,7.0,7.4$, and 7.9. For any given $\alpha$, a number of type curves are associated with appropriate $\rho_{\mathrm{s}}$ from 15 to 33 . 


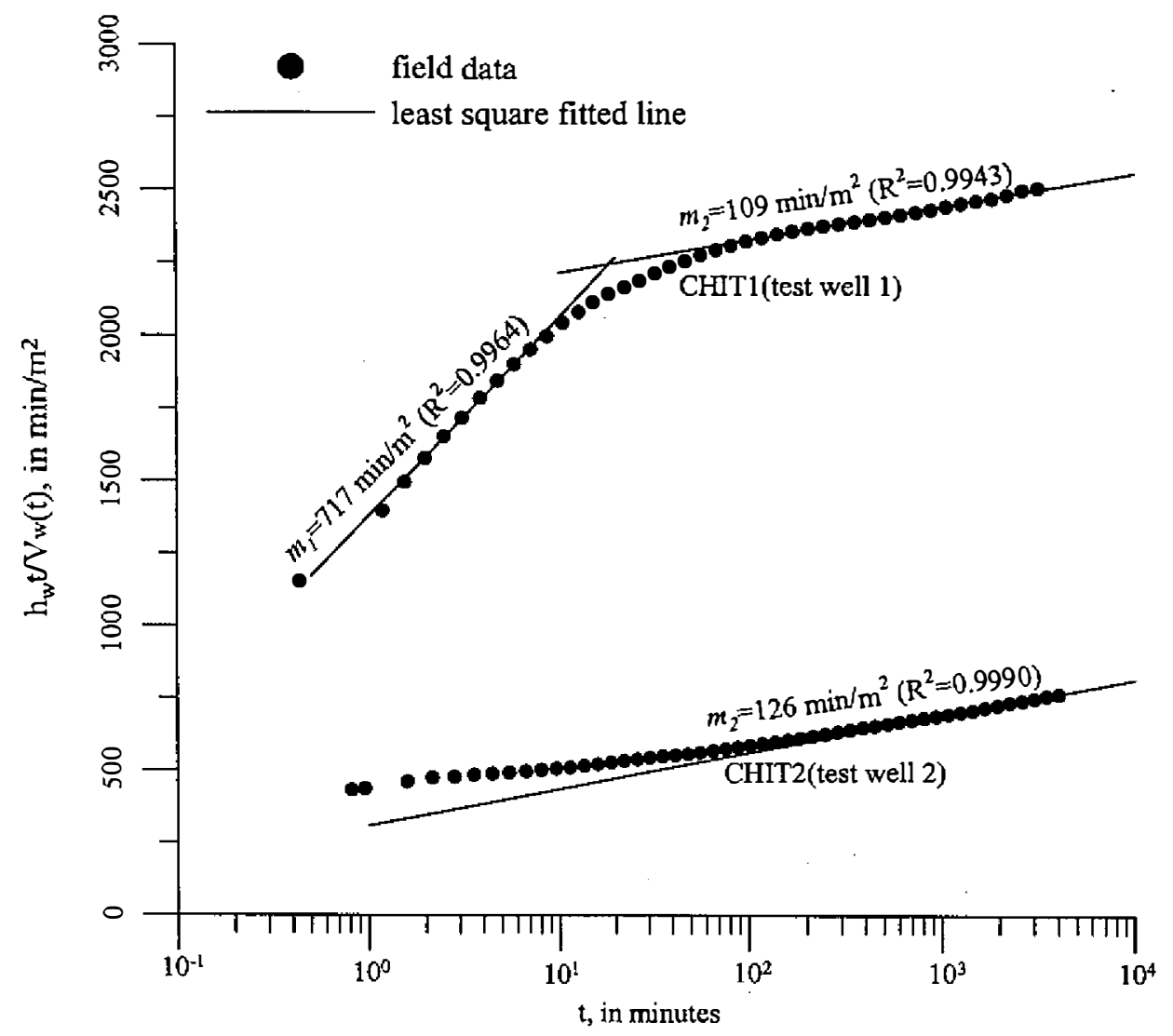

Fig. 6. Field data and data analysis of $\mathrm{h}_{\mathrm{w}} \mathrm{t} / \mathrm{V}_{\mathrm{w}}(\mathrm{t})$ from CHIT1 and CHIT2.

The curve matching follows the work described in Step 4. Taking the group of $\alpha=6.6$ as an example, the field data curve is best matched with the type curve of $\rho_{s}=33$, as shown in Fig. 7. At this matched position, $t_{m}$ is chosen as 1 minute and the associated $\tau_{m}$ as $5.2 \times 10^{2}$. The pair of $t_{m}$ and $\tau_{m}$ is arbirarily selected on the abscissa of the matched position. By (15), (16), and (17), $\mathrm{S}$ is calculated as $1.3 \times 10^{-3}$, Ts as $2.55 \times 10^{-4} \mathrm{~m}^{2} / \mathrm{min}$, and $\mathrm{r}_{\mathrm{s}}$ as $1.65 \mathrm{~m}$, respectively. This completes one set of curve matching, and the ranges of $S, r_{s}$ and $T_{s}$ are obtained by repeating the curve matching procedures for the rest three groups of type curves.

The results of matching the field data with the four groups of type curves are tabulated in Table 1. The storage coefficient falls between $1.3 \times 10^{-3}$ and $2.52 \times 10^{-3}$, appropriate for the confined condition. The skin thickness ranges from 0.85 to $1.6 \mathrm{~m}$. The skin thickness defined in the model includes the gravel pack thickness because $r_{s}$ is taken from the well bore surface at $r_{w}$ instead of from the borehole surface. If the average gravel pack thickness is assumed to be $0.1 \mathrm{~m}$ because the borehole radius is $0.15 \mathrm{~m}$ and the well bore radius is $0.05 \mathrm{~m}$, then the possible thickness of drilling mud invasion into the native aquifer varies from 0.75 to $1.5 \mathrm{~m}$. The transmissivity of the skin region ranges between $2.13 \times 10^{-4}$ and $2.55 \times 10^{-4} \mathrm{~m}^{2} / \mathrm{min}$, which is about one order of magnitude smaller than T. Thus, the skin region is considered positive skin. 


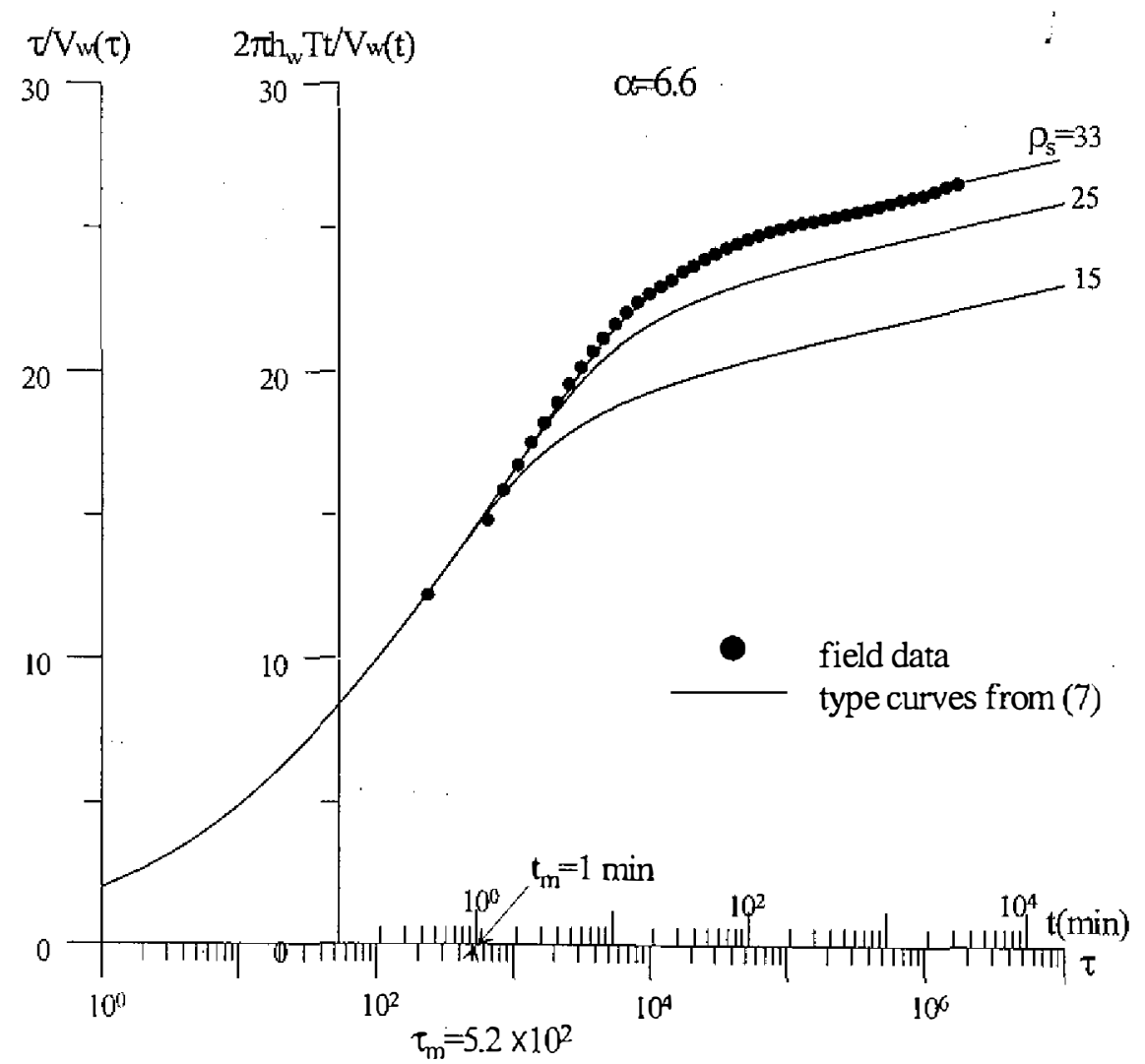

Fig. 7. Field data curve best matched with the type curve of $\rho_{s}=33$ for $\alpha=6.6$.

Based on these results, the equivalent $S_{k}$ defined by (4) varies from 19.58 to 19.94 .

The ranges obtained for $r_{s}, T, S$, and $S_{k}$ are rather narrow. Therefore, their averages are appropriately representative of the respective parameters. That is, the four parameters for the silty sand aquifer may be, for instance, $\mathrm{T}=1.68 \times 10^{-3} \mathrm{~m}^{2} / \mathrm{min}, \mathrm{S}=1.88 \times 10^{-3}, \mathrm{~T}_{\mathrm{s}}=2.34 \times 10^{-4} \mathrm{~m}^{2} /$ $\mathrm{min}$, and $\mathrm{r}_{\mathrm{s}}=1.25 \mathrm{~m}$ measured from the borehole surface. The finite skin is positive and its equivalent skin factor is 19.77 .

The field data of $h_{w} t / V_{w}(t)$ of CHIT2, however, presents a smooth curve with a straightline tail for $\mathrm{t}$ greater than about 200 minutes. This trend resembles the curve associated with the homogeneous case, as given in Fig. 2, and thus little or no skin is assumed for test well 2. By the least square method, the slope of the straight-line tail is $126 \mathrm{~min} / \mathrm{m}^{2}$, which corresponds to a $\mathrm{T}$ of $1.45 \times 10^{-3} \mathrm{~m}^{2} / \mathrm{min}$. The T determined from CHIT2 is about $14 \%$ less than the T determined from CHIT1, indicating that the aquifer is relatively homogeneous in the neighborhood of the two test wells. The straight-line tail intercepts the abscissa at $t_{2}=3.48 \times 10^{-3} \mathrm{~min}$, which gives $S=1.68 \times 10^{-3}$ by using (12). This $S$ value falls within the range of $S$ estimated with the field data of CHIT1, and is $11 \%$ less than the averaged $S=1.88 \times 10^{-3}$, supporting the results obtained by the curve matching method.

As depicted in Fig. 4, the silty sand aquifer is typical of no leakage effect because it is 
sandwiched between two clay layers. Since the second well in each nest is screened across the upper silty sand layer, no drawdown observed at the second wells of nest 1 and 2 during the tests further indicates little or no leakage across the upper clay layer. In spite of these field evidences, the Hantush (1964) model is used to quantitatively verify that the silty sand aquifer has no leakage effect because, if leakage exists, the estimation of the storage coefficient could be biased.

The Hantush (1964) model deals with a constant head pumping in an aquifer subject to leakage from the overlying aquitard. The aquitard has finite thickness $b^{\prime}$, a storage coefficient $S^{\prime}$, and a hydraulic conductivity $K^{\prime}$. On top of the aquitard, there is another aquifer in which the head remains unchanged during the test, similar to the field condition of the current study. Well skin is not taken into account in this model, and thus $\mathrm{T}=1.45 \times 10^{-3} \mathrm{~m}^{2} / \mathrm{min}$ and $\mathrm{S}=1.45 \times 10^{-3}$ as obtained from CHIT2 are used here for the silty sand aquifer.

The Laplace-domain solution of dimensionless drawdown in the aquifer is (Hantush 1964)

$$
\mathrm{h}(\rho ; \mathrm{p})=\frac{1}{\mathrm{p}} \frac{\mathrm{K}_{0}(\lambda \rho)}{\mathrm{K}_{\mathbf{0}}(\lambda)},
$$

where $\lambda=[p+\sqrt{p \sigma \beta} \operatorname{coth}(\sqrt{p \sigma / \beta})]^{0.5}, \beta=K^{\prime} r_{w}^{2} /\left(\mathrm{T} b^{\prime}\right)$, and $\sigma=S^{\prime} / \mathrm{S}$. Application of Darcy's law to (20) at $\rho=1$ gives $Q_{w}(p)$, and then $V_{w}(p)$ is determined with (6) as

$$
\mathrm{V}_{\mathrm{w}}(\mathrm{p})=\frac{\lambda}{\mathrm{p}^{2}} \frac{\mathrm{K}_{1}(\lambda)}{\mathrm{K}_{0}(\lambda)}
$$

The dimensionless parameter $\beta$ can be considered as the leakage factor representative of the leakage strength. A larger $\beta$ indicates stronger leakage, and $\beta$ is zero for no leakage. As shown in Fig. 4, if the top clay layer is considered an aquitard to the silty sand aquifer, its average thickness $b^{\prime}$ is $3 \mathrm{~m}$. Since the hydraulic conductivity of clay typically ranges from $10^{-8}$ to $10^{-11} \mathrm{~m} / \mathrm{s}$ (Fetter 1994; Freeze and Cherry 1979 ), $K^{\prime}$ is selected to be $10^{-8} \mathrm{~m} / \mathrm{s}$ for the maximum possible leakage effect. Then $\beta$ is $3 \times 10^{-7}$, which is the largest possible leakage factor in the current study. The dimensionless parameter $\sigma$ is the storage ratio of $S^{\prime} / \mathrm{S}$, and a larger $\sigma$ indicates an earlier leakage. Although the range of the specific storage of clay is not clearly documented in the literature, for the purpose of the current study $\sigma=10$ (that is, $S^{\prime}$ of clay is as ten times large as $\mathrm{S}$ of the silty sand aquifer) is large enough to check if the maximum possible leakage could occur during the test period of CHIT2.

As shown in Fig. 8, the field data of $h_{w} t / V_{w}(t)$ from CHIT2 are compared with the curves calculated by numerically inverting (21) by the Stehfest method. When $\beta=3 \times 10^{-7}$, the curve associated with $\sigma=10$ deviates from the curve of $\beta=0$ at about $t=100$ minutes. The curve of $\sigma=0$, however, delays its deviation to $t=2000$ minutes. The field data of $h_{w} t / V_{w}(t)$ from CHIT2 do not fall on these curves of $\beta=3 \times 10^{-7}$. Instead, the field data coincide with the curve with $\beta=0$, confirming that there is no leakage.

In a shallow unconfined glacial till aquifer, Jones et al. (1992) performed a CHT to determine specific yield and transmissivity. At this site, observation wells were installed at $0.9 \mathrm{~m}$, $1.83 \mathrm{~m}, 2.74 \mathrm{~m}$, and $3.66 \mathrm{~m}$ from the pumping well. The observation wells were so close to the pumping well that drawdown variations could be measured even under a small pumping rate. As such, a multiple-well CRT was conducted for the validation of the estimates from the CHT. 


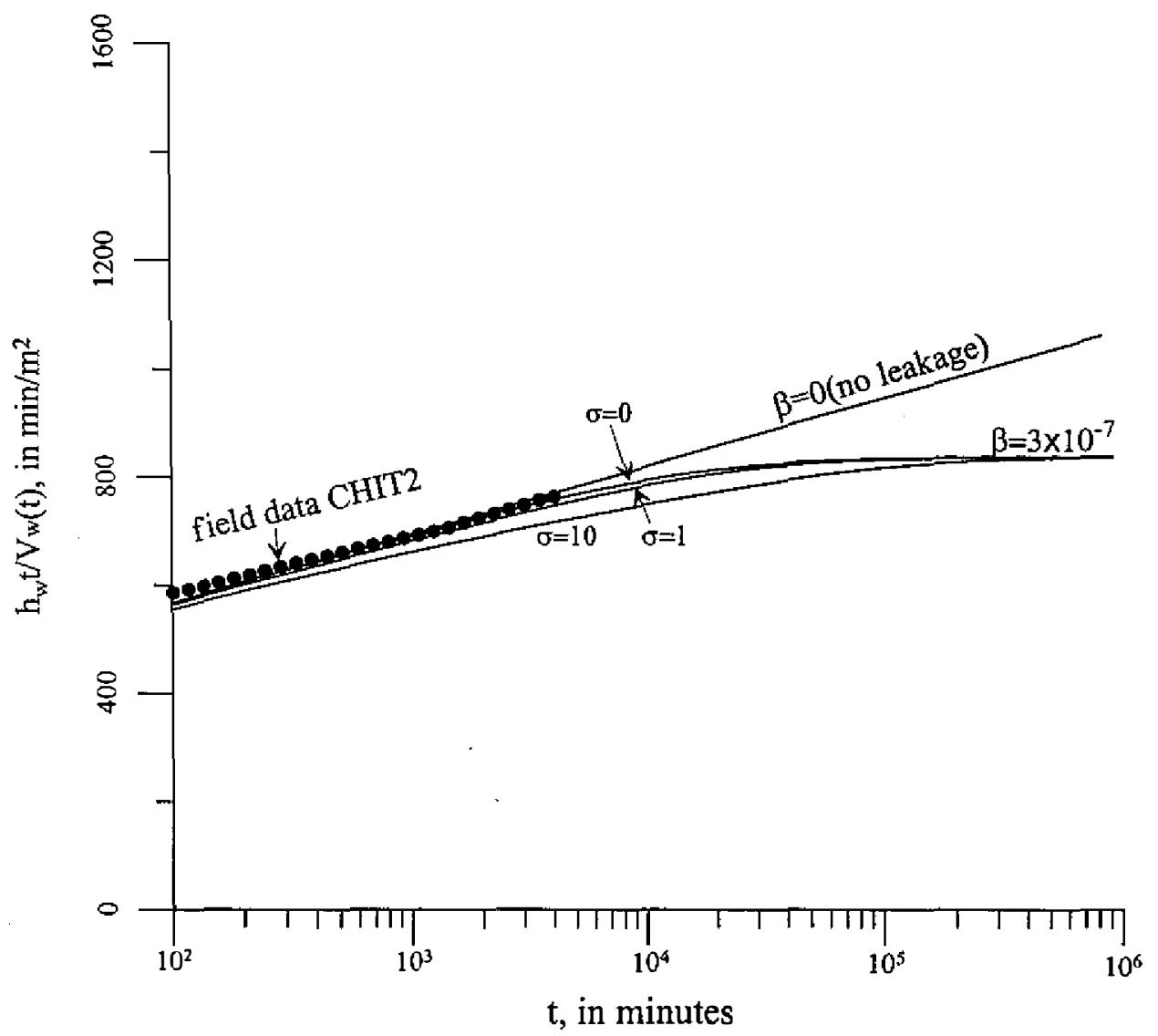

Fig. 8. Comparison of field data CHIT2 and curves of different $\beta$ and $\sigma$. Coincidence of field data and the curve of $\beta=0$ verifying that there is no leakage during CHIT2.

For the current study, however, it is rather difficult to install wells so closely spaced because of the site geology and the depth to the aquifer. Therefore, the estimates of the CHITs cannot be validated by the CRT method. However, two slug tests were performed at the test wells, respectively. The data can be used to validate the transmissivity determined from the CHITs (slug tests are not appropriate for the estimation of the storage coefficient.)

The initial head drop $\mathrm{H}_{0}$ for the slug test was $9.1 \mathrm{~m}$ at test well 1 , and was $10 \mathrm{~m}$ at test well 2. As shown in Fig. 9, the slug test data of $\log \left(\mathrm{H}_{w}(t) / \mathrm{H}_{0}\right)$ are plotted against time, where $\mathrm{H}_{w}(t)$ denotes the water level recovery at the test wells. Test well 2 has no skin, and its slug test data exhibit an upward curve that remarkably resembles the double-straight line curve as displayed in Bouwer (1989; Fig. 4) where well skin is absent. The first staight line extends from $t=0$ to about one minute with a relatively steep slope, and the second straight line spans over the period from 1 to about 12 minutes with a milder slope of $0.134 / \mathrm{min}$. Bouwer (1989) attributes the steep, first straight line to the highly permeable gravel pack around the well, which quickly 


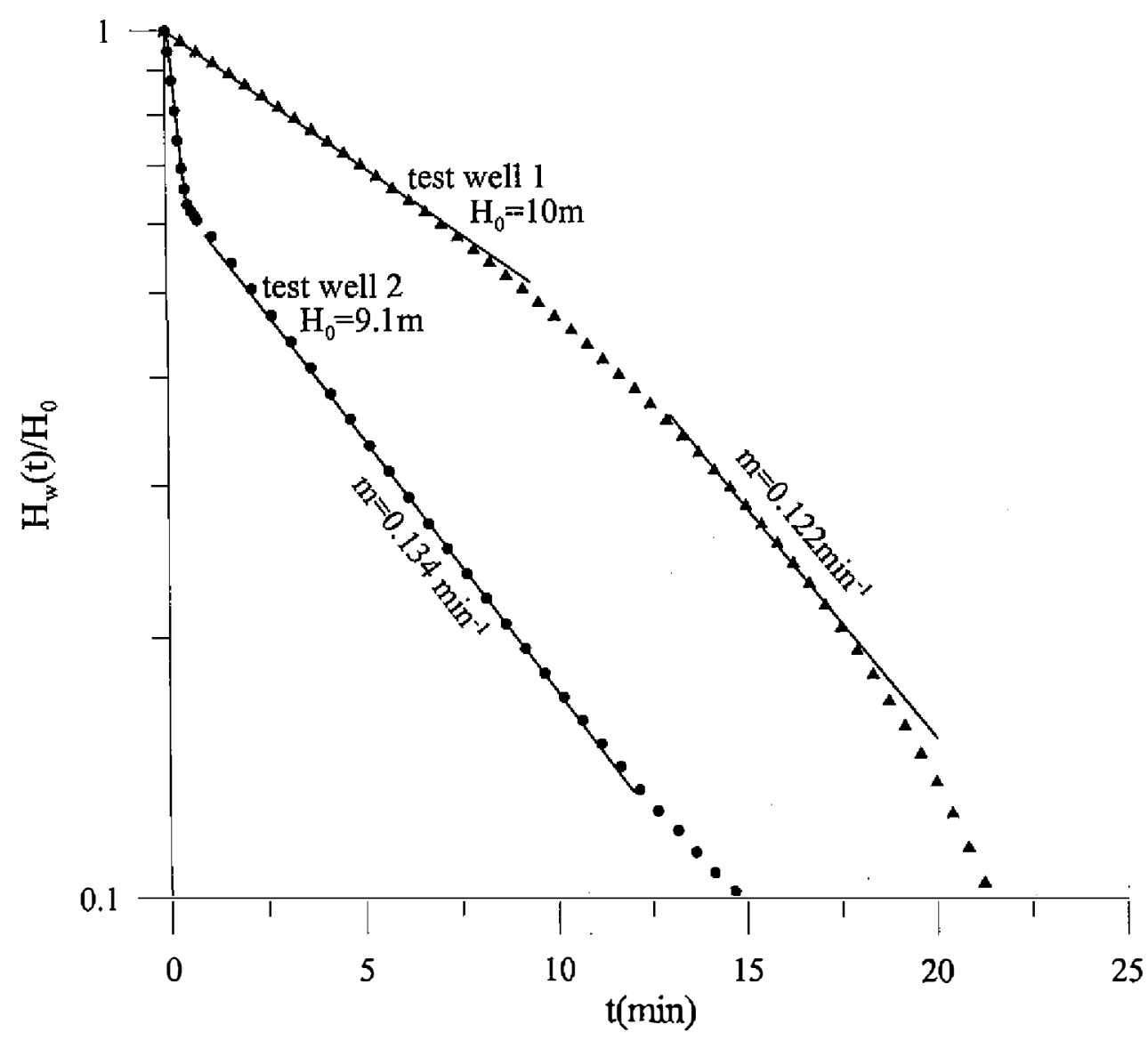

Fig. 9. Semilog plot of slug test data from test well 1 and test well 2.

sends water into the well. After the water level in gravel pack has drained to the water level in the well, the flow into the well slows down and the data points begin to form a second, less steep, straight line. This second straight line is more indicative of the native aquifer and can be applied to the Bouwer and Rice method (1976) for calculating $T$ (Bouwer 1989). As a result, the $T$ value determined from the slug test at test well 2 is $1.89 \times 10^{-3} \mathrm{~m}^{2} / \mathrm{min}$, slightly higher than the $1.68 \times 10^{-3} \mathrm{~m}^{2} / \mathrm{min}$ estimated from the CHITs.

Test well 1 has skin effects, and its slug test data demonstrate a concave downward curve that is similar to the type curves presented by Yang and Gates (1997) for slug tests in wells of skin effects. The early water level recovery is retarded compared to the late water level recovery. This is because in the early times groundwater flow is restricted to the less permeable skin region. Yang and Gates (1997) indicated that the late- time data are closely reflective of groundwater flow in the native aquifer, and the Bouwer and Rice (1976) method can be applied to estimate transmissvity. For test well 1 , the slug test data from about 12 to 16 minutes appear as a straight line representative of the late-time data. Then, by the Bouwer and Rice (1976) method, 
$\mathrm{T}$ is determined as $1.72 \times 10^{-3} \mathrm{~m}^{2} / \mathrm{min}$, very close to $1.68 \times 10^{-3} \mathrm{~m}^{2} / \mathrm{min}$. Therefore, the CHIT proposed here yields a transmissivity value that is in good agreement with that calculated from the slug tests, supporting the validity of the estimates from the CHITs.

\section{CONCLUSIONS}

The following conclusions can be drawn from the preceding discussion:

1. Overflowing the test well is relatively easy, and thus simplifies the process of securing a constant head, rendering the CHIT an easy aquifer test in low-T aquifers where the conventional CRT usually fails. In addition, the difference between the injection rate and the overflow rate directly yields the cumulative volume $V_{w}(t)$ entering the aquifer. The $V_{w}(t)$ is characteristic of the aquifer hydrogeologic properties and can be used for parameter estimation.

2. If the semilog plot of $t / V_{w}(t)$ or $h_{w} t / V_{w}(t)$ displays an early-time and a late-time straight-line segments joined by a smooth curve at intermediate time, a skin region of a thickness greater than $15 \mathrm{r}_{\mathrm{w}}$ possibly exists around the test well, and the finite skin approach is appropriate for modeling the problem of interest. If the semilog plot of $t / V_{w}(t)$ exhibits only a smooth curve with a straight-line tail at large time, either the skin region is absent or it can be simulated by using the infinitesimal skin approach.

3. Without well skin, the two unknown parameters $\mathrm{T}$ and $\mathrm{S}$ can be uniquely determined using $\mathrm{V}_{\mathrm{w}}$ (t). If well skin exists, however, there are four unknown parameters, among which only $\mathrm{T}$ can be uniquely determined while the remaining $T_{s}, r_{s}$, and $S$ are obtained in appropriate ranges. In order to avoid non-unique results for the aquifer parameters, the test well should be carefully constructed with complete and thorough well development to prevent well skin from forming.

4. While the CHIT is a useful means for parameter estimation in both low- and high-transmissivity aquifers, more detailed validation of the parameter estimation is recommended. Due to the limitation of the site hydrogeology, we are only able to perform slug tests for the sake of validation. The $\mathrm{T}$ values determined by the CHITs and by the slug tests are in good agreement. However, $\mathrm{S}$ determined from the CHIT remains unverified because the slug test is not suitable for estimating the storage coefficient. For future research, it is suggested that a CHIT and a multiple-well CRT be performed in a high-transmissivity aquifer. Then, $\mathrm{T}$ and $\mathrm{S}$ determined from the multiple-well $\mathrm{CRT}$ can be used for validating $\mathrm{T}$ and $\mathrm{S}$ obtained from the CHIT.

\section{Dimensional}

\section{Nomenclature}

b aquifer thickness, L.

$b^{\prime} \quad$ aquitard thickness, L. 
$h_{w} \quad$ constant head of the constant-head well, $L$.

$\mathrm{H}_{\mathrm{T}} \quad$ constant head in the discharge tank, $\mathrm{L}$.

$\mathrm{H}_{0} \quad$ initial head drop of the slug test, $\mathrm{L}$.

$\mathrm{H}_{w}(\mathrm{t}) \quad$ water level recovery of the slug test, $\mathrm{L}$.

$K^{\prime} \quad$ hydraulic conductivity of the aquitard, $\mathrm{L} / \mathrm{T}$.

$m_{1} \quad$ slope of the straight line at small time, $T / L^{3}$.

$\mathrm{m}_{2} \quad$ slope of the straight line at large time, $\mathrm{T} / \mathrm{L}^{3}$.

$\mathrm{Q}_{\mathrm{i}}(\mathrm{t}) \quad$ inflow rate, $\mathrm{L}^{3} / \mathrm{T}$.

$\mathrm{Q}_{0}(\mathrm{t}) \quad$ overflow rate, $\mathrm{L}^{3} / \mathrm{T}$.

$\mathrm{Q}_{\mathrm{s}} \quad$ constant flow rate supplied to the measurement tank, $\mathrm{L}^{3} / \mathrm{T}$.

$\mathrm{Q}_{w}(\mathrm{t}) \quad$ flow rate of the constant-head well, $\mathrm{L}^{3} / \mathrm{T}$.

$\mathrm{r}$ radial distance, $\mathrm{L}$.

$r_{s} \quad$ radius of the skin region, $L$.

$\mathrm{r}_{\mathrm{w}} \quad$ radius of the well, $\mathrm{L}$.

S storage coefficient of the aquifer and the skin region.

$S^{\prime} \quad$ storage coefficient of the aquitard.

t time, $\mathrm{T}$.

$\mathrm{t}_{2}$ the abscissa interception of the late-time straight line, $\mathrm{T}$.

$\mathrm{t}_{\mathrm{m}} \quad$ time associated with at the match point, $\mathrm{T}$.

$\mathrm{T}$ the aquifer transmissivity, $\mathrm{L}^{2} / \mathrm{T}$.

$\mathrm{T}_{\mathrm{s}} \quad$ the skin region transmissivity, $\mathrm{L}^{2} / \mathrm{T}$.

$V_{w}(t) \quad$ cumulative volume of the constant-head well, $L^{3}$.

$\mathrm{w}(\mathrm{t}) \quad$ water weight change in the measurement tank, $\mathrm{Mg}$.

$\mathrm{W}_{0} \quad$ initial water weight in the measurement tank, $\mathrm{Mg}$.

$\gamma_{\mathrm{w}} \quad$ specific weight of water, $\mathrm{Mg} / \mathrm{L}^{3}$.

\section{Dimensionless}

$\mathrm{I}_{0}(\mathrm{x}) \quad$ modified Bessel function of the first kind of order 0 .

$I_{1}(x) \quad$ modified Bessel function of the first kind of order 1 .

$\mathrm{K}_{0}(\mathrm{x}) \quad$ modified Bessel function of the second kind of order 0 .

$\mathrm{K}_{1}(\mathrm{x}) \quad$ modified Bessel function of the second kind of order 1 .

$\mathrm{p} \quad$ Laplace transform parameter for $\tau$.

$\mathrm{Q}_{\mathrm{w}}(\mathrm{p}) \quad$ solution of $\mathrm{Q}_{\mathrm{w}}(\tau)$ in the Laplace domain.

$\mathrm{Q}_{\mathrm{w}}(\tau) \quad \mathrm{Q}_{\mathrm{w}}(\mathrm{t}) / 2 \pi \mathrm{h}_{\mathrm{w}} \mathrm{T}$.

$\mathrm{S}_{\mathrm{k}} \quad$ skin factor.

$\mathrm{V}_{\mathrm{w}}(\mathrm{p}) \quad$ solution of $\mathrm{V}_{\mathrm{w}}(()$ in the Laplace domain.

$\mathrm{V}_{\mathrm{w}}(\tau) \quad \mathrm{V}_{\mathrm{w}}(\mathrm{t}) / 2 \pi \mathrm{r}_{\mathrm{w}}{ }^{2} \mathrm{~h}_{\mathrm{w}} \mathrm{S}$. 


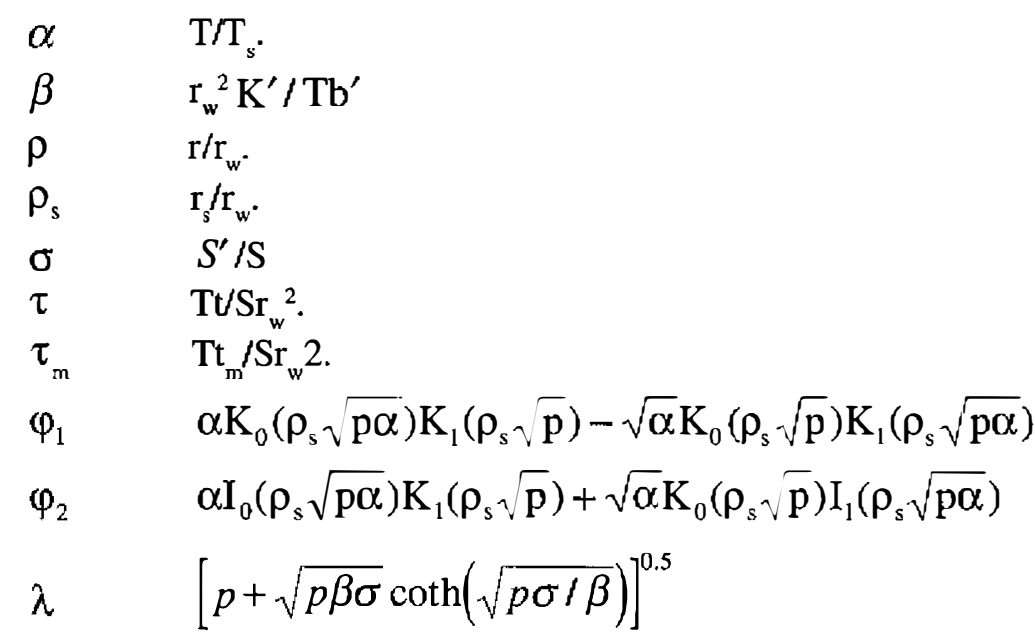

Acknowledgment The work presented is part of the project, NSC 87-2611-M-008-001, supported by National Science Council. The support is highly appreciated.

\section{REFERENCES}

Bear, J., 1972: Dynamics of Fluids in Porous Media, Dover Publications, INC., 764pp.

Bourdet, D., J. A. Ayoub, and Y. M. Plrard, 1989: Use of pressure derivative in well-test interpretation. SPE Form. Eval., June, 293-302.

Bouwer, H., and R. C. Rice, 1976: A slug test for determining hydraulic conductivity of unconfined aquifers with completely or partially penetrating wells. Water Resour. Res., $12,423-428$.

Bouwer, H., 1989: The Bouwer and Rice slug test- an update. Ground Water, 27(3), 304-309.

Chu, W. C., J. Garcia-Rivera, and R. Raghavan, 1980: Analysis of interference test data influenced by wellbore storage and skin at the flowing well. J. Pet. Tech., Jan., 171-178.

Cooper, H. H., Jr., and C. E. Jacob, 1946: A generalized graphical method for evaluating formation constants and summarizing well-field history. Trans. AGU, 27(4), 526-534.

Ehlig-Economides, C. A., and H. J. Ramey, Jr., 1981: Transient rate decline analysis for wells produced at constant pressure. Soc. Pet. Eng. J., Feb., 98-104.

Earlougher, R. C., Jr., 1977: Advances in Well Test Analysis, Monograph Series, vol. 5, Society of Petroleum Engineers, Dallas.

Fetter, C. W., 1994: Applied Hydrogeology, Prentice-Hall, New Jersey, 691pp.

Freeze, R. A., and J. A. Cherry, 1979: Groundwater, Prentice-Hall, Englewood Cliffs, 604pp. Hantush, M. S., 1959: Nonsteady flow to flowing wells in leaky aquifers. J. Geophys. Res., 64, 1043-1052.

Hantush, M. S., 1964: Hydraulics of Wells, in Advances in Hydroscience, vol. 1, edited by V. 
T. Chow, Academic Press, New York, 281-432.

Hawkins, M. F., Jr., 1956: A note on the skin effect, Trans. Am. Inst. Min. Metall. Pet. Eng., 207, 356-357.

Hurst, W., J. D. Clark, and E. B. Brauer, 1969: The skin effect in producing wells. J. Pet. Tech., Nov., 1483-1489.

Jacob, C. E., and S. W. Lohman, 1952: Nonsteady flow to a well of constant drawdown in an extensive aquifer. Trans. $A G U, 33(4), 559-569$.

Jones, L., T. Lemar, and C-T. Tsai, 1992: Results of two pumping tests in Wisconsin age weathered till in Iowa. Ground Water, 30(4), 529-538.

Jones, L., 1993: A comparison of pumping and slug tests for estimating the hydraulic conductivity of unweathered Wisconsin age till in Iowa. Ground Water, 31(6), 896-904.

Juan, V. C., 1954: Physiography and Geology of Taiwan, Silo-American Publishing Company, Taipei, Taiwan.

Kruseman, G. P., and N. A. de Ridder, 1990: Analysis and Evaluation of Pumping Test Data, ILRI publication 47, $377 \mathrm{pp}$.

Mucha, I., and E. Paulikova, 1986: Pumping test using large diameter production and observation wells. J. Hydrol., 89, 157-164.

Murdoch, L. C., and J. Franco, 1994: The analysis of constant drawdown wells using instantaneous source functions. Water Resour. Res., 30(1), 117-124.

Narasimhan, T. N., and M. Zhu, 1993: Transient flow of water to a well in an unconfined aquifer: Applicability of some conceptual models. Water Resour. Res., 29(1), 179-191.

Novakowski, K. S., 1989: A composite analytical model for analysis of pumping tests affected by well bore storage and finite thickness skin. Water Resour. Res., 25(9), 19371946.

Novakowski, K. S., 1993: Interpretation of the transient flow rate obtained from constanthead tests conducted in situ in clays. Can. Geotech. J., 30, 600-606.

Olarewaju, J. S., and W. J. Lee, 1989: A comprehensive application of a composite reservoir model to pressure-transient analysis. SPE Reserv. Eng., 4(3), 325-331.

Stehfest, H., 1970: Numerical inversion of Laplace transforms. Commun. ACM, 13(1), 47-49.

Streltsova, T. D., 1988: Well Testing in Heterogeneous Formations, John Wiley \& Sons, 413 pp.

Tavenas, F., P. Jean, P. Leblond, and S. Leroueil, 1983: The permeability of nature soft clays. Part II: Permeability characteristics. Can. Geotech. J., 20, 645-660.

Tavenas, F., M. Diene, and S. Leroueil, 1990: Analysis of the in situ constant-head permeability test in clays. Can. Geotech. J., 27, 305-314.

Tiab, D., and A. Kumar, 1980: Application of the function to interference analysis. J. Pet. Tech., Aug., 1465-1470.

Uraiet, A. A., and R. Raghavan, 1980: Unsteady flow to a well producing at a constant pressure. J. Pet. Tech., Oct., 1803-1812.

van Everdingen, A. F., 1953: The skin effect and its influence on the productive capacity of a well. Trans. Am. Inst. Min. Metall. Pet. Eng., 198, 171-176. 
van Everdingen, A. F., and W. Hurst, 1949: The application of the Laplace transformation to flow problems in reservoirs. Trans. Am. Inst. Min. Metall. Pet. Eng., 186, 305-324.

Wilkinson, W. B., 1968: Constant head in situ permeability tests in clay strata. Geotechnique, 18, 172-194.

Wylie, C. R., and L. C. Barrett, 1982: Advanced Engineering Mathematics, McGraw-Hill, $1103 \mathrm{pp}$.

Yang, Y. J., and T. M. Gates, 1997: Wellbore skin effect in slug-test data analysis for lowpermeability geologic materials. Ground Water, 35(6), 931-937. 